\title{
Feeling positive towards time: How time attitude profiles are related to mental health in adolescents
}

\author{
Claudia Tejada-Gallardo *, Ana Blasco-Belled, Carles Alsinet \\ Universitat de Lleida, Avinguda de l'estudi general, $n^{\circ}$ 4, 25001, Lleida, Spain
}

\section{A R T I C L E I N F O}

\section{Keywords:}

Time attitudes

Mental health

Well-being

Psychological distress

Adolescents

\begin{abstract}
A B S T R A C T
Introduction: Time attitudes refer to the way individuals feel about their past, present, and future and have been associated with adolescent-specific developmental, social, and emotional changes. The dual-factor model of mental health proposes that optimal functioning entails high levels of emotional, social, and psychological well-being, as well as low levels of psychopathology. Since previous research has suggested that time attitudes can assist in understanding the development of adolescents, the primary objective of this study was to examine the relationship between time attitudes and mental health according to the dual-factor model. Methods: A total of 317 Spanish high school students aged between 14 and 16 years (45.1\% females) participated in the study. Time attitudes were assessed with the Adolescent and Adult Time Inventory-Time Attitudes Scale, and profiles were identified through person-centered analysis. Data were also gathered on wellbeing and psychological distress measures, which were analyzed as distal outcomes. Results: Four time attitude profiles were identified - negatives, positives, past negatives, and present/ future negatives. Adolescents belonging to the positive profile reported higher scores on wellbeing and lower scores on psychological distress. The psychological well-being and depression constructs had higher (positive and negative, respectively) scores across all profiles. These results suggested an association between time attitude profiles and mental health according to the dualfactor model. Conclusions: We suggest that positive psychology interventions may nudge adolescents towards a more positive appraisal of the past, present, and future and promote their mental health and positive development. Further practical implications are discussed.
\end{abstract}

Time perspective is understood as an individual's thoughts and feelings about the past, the present, and the future (Zimbardo \& Boyd, 1999). The study of adolescence has brought forth a conceptual model of time perspective with additional dimensions that is relevant to that period of life (Mello \& Worrell, 2015). A rapidly growing number of studies have examined the relationship between time attitudes and adolescent-specific developmental outcomes (e.g., Andretta et al., 2014), but less attention has been paid to mental health. The latter is defined as the combination of high levels of emotional, social, and psychological well-being and low levels of psychopathology - as conceptualized by the dual-factor model of mental health (Keyes, 2009; World Health Organization [WHO], 2004). Within this framework, well-being can be understood as the subjective perception of one's life conditions (Ng \& Fisher, 2013). Generally, adolescents experience decreased well-being (Chen \& Page, 2016; González-Carrasco et al., 2019) and increased psychological distress, which entails a discomforting emotional experience in response to life stressors and can ultimately result in psychological disorders or impaired daily functioning (Hammen, 2005). On this basis, we sought to examine the relationship between time

\footnotetext{
* Corresponding author.

E-mail address: claudia.tejada@udl.cat (C. Tejada-Gallardo).
} 
attitudes and mental health in adolescents. To that end, time attitudes can be assessed using a person-centered approach to identify different profiles according to how adolescents feel about their past, present, and future.

\section{Adolescents' time perspectives}

Time attitudes have recently been incorporated into research as an independent phenomenon, having initially been subsumed within a broader construct, namely, time perspective (Mello \& Worrell, 2015). Time perspective is a multi-dimensional construct that emerges from cognitive processes in which human experience is divided into past, present, and future time frames and influences specific behaviors through the way that individuals think and feel about time (Zimbardo \& Boyd, 1999). The construct of time perspective is regarded as a developmental phenomenon that is particularly salient in adolescence (Piaget, 1955) - a period characterized by identity formation that allows adolescents to form a perspective on time different from the one they had in childhood (Mello \& Worrell, 2015). The Zimbardo time perspective inventory (ZTPI; Zimbardo \& Boyd, 1999) is the first comprehensive and theory-based operationalization of time perspectives and comprises five dimensions (i.e., past negative, past positive, present hedonistic, present fatalistic, and future). Within these dimensions, the most adaptive attitude towards temporal frames is commonly referred to as the balanced time perspective (BTP; Zimbardo \& Boyd, 1999). The BTP has been proposed as a more adaptive and positive alternative to coping with the demands of life since it represents a combination of high scores on past positive, present hedonistic, and future and low scores on past negative and present fatalistic (Boniwell \& Zimbardo, 2004). Nevertheless, the model proposed by Zimbardo and Boyd (1999) has demonstrated limited utility in adolescent samples, indicating that ZTPI scores are not always reliable. Moreover, the structural validity of the model, which lacks a negative dimension towards the future, did not support the original structure of the scale (Mello \& Worrell, 2007). Accordingly, Mello and Worrell (2015) presented a new conceptual model of time perspective for adolescents. This model proposes that time perspective is composed of the three time frames (i.e., past, present, and future) in five dimensions (i.e., time attitudes, time orientation, time relation, time frequency, and time meaning). Time attitudes refer to individuals' positive and negative feelings towards the past, present, and future and can be assessed using a self-administered questionnaire (Mello \& Worrell, 2015).

\section{Time attitude profiles}

The study of feelings towards time has gained attention with particular regard to adolescence in an effort to describe how time attitudes promote adolescent-specific developmental, social, and emotional changes (e.g., Andretta et al., 2014; Worrell et al., 2019). Research on adolescents has employed Mello and Worrell's (2015) time attitudes measure to investigate several developmental outcomes through a person-centered approach. Time attitude profiles have been associated with academic achievement and self-esteem, suggesting that positive profiles (i.e., positive and optimistic) reflect higher academic expectations and self-esteem than negative profiles (i.e., negative and pessimistic; Andretta et al., 2014). Other studies on risk-taking behaviors demonstrated that certain profiles were associated with less alcohol use. In fact, the positive profiles are associated with the highest proportion of alcohol abstainers (McKay et al., 2019). Morgan et al. (2019) also demonstrated that individuals clustered in the positive profile had higher self-efficacy and were less sensation-seeking than those clustered in negative profiles. In short, studies on time attitude profiles have indicated that positive profiles are associated with more adaptive outcomes.

Several profiles have been observed across time attitude studies involving adolescents (Andretta et al., 2014; Konowalczyk et al., 2019; McKay et al., 2019, Wells et al., 2018). These profiles include the following: positive - agreeable feelings towards all time frames; balanced - similar feelings towards each time frame; ambivalent - a lack of strong feelings towards all three time frames; and negative - disagreeable feelings towards all time frames. Although previous research has yielded equal profiles across studies (e.g., McKay et al., 2019; Morgan et al., 2016; Wells et al., 2018), establishing a common pattern of clusters is difficult because variations across profiles are likely in adolescent samples. A few studies found more specific profiles, such as negative future profiles, which are characterized by high scores for the negative (past and present) time frames and near zero for the positive (past and present) time frames. With regard to the future time frame, both positive and negative attitudes scored above zero (McKay et al., 2019; Morgan et al., 2019; Wells et al., 2018). Previous studies also identified past negative profiles, characterized by high scores on past negative and low scores on past positive, while all other time frames were near zero (Konowalczyk et al., 2019; Worrell et al., 2019). Finally, present/future negative profiles were characterized by high scores for both present and future negative and low scores for present and future positive, while all other time frames were near zero (Worrell et al., 2019).

Research on time attitudes employs person-centered analysis, such as latent profile analysis (LPA), to identify types of individuals who display similar positive and negative feelings towards the past, present, and future (i.e., latent profiles) and therefore describe the 
organization of time attitudes within individuals (Lanza et al., 2010; Mello \& Worrell, 2015). A person-centered approach focuses on identifying differences between profiles in which the analyzed variables are treated as characteristics of those individuals rather than merely outcomes (Laursen \& Hoff, 2006). In our study, participants were categorized into profiles sharing similar time attitudes. Additionally, it is possible to predict membership of profiles according to selected variables of interest (Wang \& Hanges, 2011). These variables are known as distal outcomes and represent the consequences of latent profile membership rather than the indicators of latent profiles. Analyzing a distal outcome of latent profiles indicates how the confluence of time attitudes at an initial point predicts the outcome of interest over time (i.e., mental health; Lanza et al., 2013).

\section{The dual-factor model of mental health and time attitudes}

The dual-factor model provides a conceptualization of mental health that is defined by the presence of positive factors (i.e., emotional, social, and psychological well-being) and the absence of clinical risk factors (e.g., depression and anxiety disorders; Westerhof \& Keyes, 2010). According to this conceptualization, mental health is more than the mere absence of psychopathology, and therefore mental health and psychopathology are studied as related but empirically distinct constructs (WHO, 2004). Since the absence of psychopathology in youth does not necessarily indicate a state of complete mental health (Keyes, 2009), considering the promotion of (emotional, social, and psychological) well-being in assessments of adolescents' mental health has become imperative within the movement towards positive youth development and effective learning (Clonan et al., 2004; Keyes, 2009; Suldo et al., 2016).

During the transition from adolescence to adulthood, there is a high prevalence of mental illness (Pearson et al., 2013), specifically depression, which has its highest rates among adolescents (Birmaher et al., 1996). Depression has detrimental consequences for the daily functioning of young people (Derdikman-Eiron et al., 2013). It is estimated that over 3\% of females and $4.5 \%$ of males between the ages of 15 and 19 years old suffer from depression, while 5.5\% of females and 3.5\% of males suffer from anxiety disorders (WHO, 2017). As the number of adolescents affected by depression, anxiety, and stress has increased in recent years, these conditions are becoming a societal burden (Stewart et al., 2013; WHO, 2017). Unlike in childhood, in adolescence, the social and psychological components of well-being seem to dominate, whereas the emotional component tends to decrease (Hallam et al., 2014). Of the three components of well-being, psychological well-being seems to be the most common among late adolescents (González-Carrasco et al., 2019). On the other hand, psychological distress, which includes depression, anxiety, and stress symptoms and is considered as marking the onset of mental illness, can appear during adolescence (Paus et al., 2008; Shapero et al., 2013).

Adolescents face increasing demands to satisfy the needs of normative adjustment, including academic and social adjustment and identity formation (La Guardia \& Ryan, 2002). All these demands have been linked to decreased emotional, social, and psychological well-being (Chen \& Page, 2016; González-Carrasco et al., 2019) and to exacerbated psychological distress (Hammen, 2005; Suldo et al., 2016). Time attitude profiles have previously been associated with well-being in early and late adolescence, demonstrating that having a positive profile is related to optimal outcomes in terms of well-being (i.e., general well-being and somatic and psychological symptoms; Konowalczyk et al., 2018; Worrell et al., 2019). Although the relationship between time attitudes and depression, anxiety, and stress has been investigated, no existing evidence accounts for the contribution of time attitudes to the specific indicators of emotional, social, and psychological well-being in adolescents. Being able to relate a positive time attitude profile to greater well-being and lower psychological distress would be beneficial for practitioners working with adolescents, in that promoting a positive appraisal of the past, present, and future may foster the optimal psychological adjustment necessary in this developmental stage.

\subsection{The current study}

The goal of this study is to investigate the relationship between time attitude profiles and mental health in a sample of adolescents. Previous research on time attitudes has found variability of adolescents' profiles that precludes generalizations. In addition, the relationship between time attitude profiles and mental health (i.e., well-being and psychological distress) has not previously been explored using the dual-factor model (Keyes, 2002, 2009). In this study, we first identified the time attitude profiles of Spanish adolescents - that is, we identified groups of individuals with similar feelings and attitudes (positive and negative) towards the past, present, and future. Second, we examined the associations between the identified time attitude profiles and the dual-factor model of mental health - in other words, how the profiles predicted indicators of mental health and mental illness. Based on prior research on time attitudes, our first hypothesis was that clusters of positive profiles would be associated with higher levels of emotional, social, and psychological well-being and lower levels of depression, anxiety, and stress. Based on research on adolescents' well-being, our second 
hypothesis was that the constructs of psychological well-being and depression would score more highly than other variables.

\section{Methods}

\subsection{Participants and procedure}

A total of 317 Spanish adolescents $(M=15.07 ; S D=0.64 ; 45.1 \%$ females $)$ participated in the study. Specific demographics are presented in Table S1. The participants were final-year students from four high schools in west Catalonia (Spain). The adolescents were involved in a school program aimed at assessing and promoting mental health in high schools. The participants and their parents received consent information from the high schools, with the option to leave the study whenever they desired. An informed consent form signed by the parents or a legal guardian was required for an adolescent to participate in the study.

\subsection{Measures}

Time attitudes were measured with the Adolescent and Adult Time Inventory-Time Attitudes Scale (AATI-TA; Mello \& Worrell, 2007; Spanish adaptation of Mello et al., 2010). The AATI-TA consists of six subscales that assess past positive, past negative, present positive, present negative, future positive, and future negative. The scale is comprised of 24 items with a 5 -point Likert scale $(1=$ totally disagree, $5=$ totally agree). The Cronbach's $\alpha$ reliability estimates of the AATI-TA for the present study were 0.86 for the past positive, 0.92 for the past negative, 0.89 for the present positive, 0.75 for the present negative, 0.88 for the future positive, and 0.80 for the future negative. The following sample items are representative of each subscale: "I have very happy memories of my childhood" for past positive, "I wish that I did not have the past that I had" for past negative, "I am happy with my current life" for present positive, "I am not satisfied with my present" for present negative, "Thinking about my future excites me" for future positive, and "Thinking about my future makes me sad" for future negative.

Well-being was measured with the Mental Health Continuum - Short Form (MHC-SF; Keyes et al., 2008; Spanish adaptation of Echeverría et al., 2017). The MHC-SF consists of three subscales that assess emotional, social, and psychological well-being. The scale is comprised of 14 items, and respondents rate the frequency of each feeling in the past month on a 6 -point Likert scale $(1=$ never, $6=$ every day). The Cronbach's $\alpha$ reliability estimates of the MHC-SF for the present study were 0.80 for emotional well-being, 0.73 for social well-being, and 0.81 for psychological well-being. The following sample items are representative of each subscale: "In the past month ... how often did you feel happy?" for emotional well-being, “... how often did you feel that you had something important to contribute to society?" for social well-being, and “... how often did you feel that you liked most parts of your personality?" for psychological well-being.

Psychological distress was measured by the Depression Anxiety Stress Scale (DASS-21; Lovibond \& Lovibond, 1995; Spanish adaptation of Daza et al., 2002). The DASS-21 assesses the levels of symptomatology associated with depression, anxiety, and stress during the past week. This scale is comprised of 21 items, and responses are based on a 4-point Likert scale $(0=$ did not apply to me at all, 3 = applied to me very much, or most of the time). The Cronbach's $\alpha$ reliability estimates of the DASS-21 for the present study were 0.83 for depression, 0.74 for anxiety, and 0.75 for stress. The following sample items are representative of each subscale: "Over the past week ... I couldn't seem to experience any positive feeling at all” for depression, “... I was worried about situations in which I might panic and make a fool of myself" for anxiety, and "... I found it hard to wind down" for stress.

\subsection{Statistical analysis}

All of the data and syntaxes necessary to replicate the results are available to download in an open repository at: https://osf.io/ ux263/?view_only=1b3a2c1da9c345db866149cc9aebfb0b (the link was blinded for peer review purposes). Confirmatory factor analysis (CFA) and LPA were conducted using maximum likelihood estimation with robust standard errors in Mplus Version 7.2 (Muthén \& Muthé). We first assessed the measurement structure of each scale following standard recommendations of model fit evaluation. The lower bound for acceptable model fit for the comparative fit index (CFI) and the Tucker-Lewis index (TLI) was set to 0.90, while the upper bound for acceptable model fit for the standardized root mean square residual (SRMR) was set to 0.08 and to 0.05 for the root mean square error of approximation (RMSEA; Marsh et al., 2004). To compare competitive models, we used the Bayesian information criterion (BIC), in which lower values indicate better model fit (Byrne, 1995; Kline, 2011). Based on prior research, we assessed the two-, three-, and six-factor models of the AATI-TA (Mello \& Worrell, 2007); the three-factor model of the MHC (Keyes et al., 2008); and the three-factor model of the DASS-21 (Lovibond \& Lovibond, 1995). 
Second, subgroups of high school students were identified using LPA to test the first hypothesis. LPA uses a type of finite mixture model and a variant of latent class analysis for continuous variables to identify clusters (i.e., latent profiles) and classify individuals based on responses for a series of continuous variables (i.e., indicators: past positive, past negative, present positive, present negative, future positive, and future negative). Despite being similar to CFA, LPA explains population heterogeneity by identifying the underlying unobserved categorical variable that divides a population into subgroups of individuals who are similar in their responses for a set of observed variables (Oberski, 2016). It is considered "a person-centered analytic tool that focuses on similarities and differences among people instead of relations among variables" (Berlin et al., 2014, p. 174).

Latent profiles of the AATI-TA were analyzed, and between two and seven profiles were tested. To determine the optimal number of latent profiles, each model was assessed using the following indicators: the Akaike information criterion (AIC), the BIC, the adjusted BIC (aBIC), the Lo-Mendell-Rubin likelihood ratio test (LMR), the adjusted LMR (aLMR), and the bootstrap likelihood ratio test (BLRT). Lower values on the AIC, BIC, and aBIC indicate an overall better profile solution. However, these indicators often keep improving with the addition of more profiles. The LMR and BLRT were used to compare the models of the $k$ profile and the $k-1$ profile. A significant $p$-value suggests that the $k$ profile model is better than the $k-1$ profile model. Put differently, comparing the estimated model (e.g., five classes) with a model with one less class (e.g., four classes) and obtaining a non-significant $p$-value ( $p>$ .050) indicates that the model with one less class should be accepted. Of the likelihood-based tests, the BLRT was found to be the best indicator of the appropriate number of profiles (Nylund et al., 2007). Finally, entropy highlights the precision of the classification of individuals into latent profiles, with values ranging from 0 (i.e., lower accuracy) to 1 (i.e., higher accuracy; Tein et al., 2013). To facilitate the labelling of profiles, time attitude factor means were standardized into $T$-scores $(M=50, S D=10)$ and the criteria of \pm 0.5 SDs around the mean for each factor was followed, so that positive values were above $0.5 \mathrm{SD}$ and negative values were below 0.5 SD (e. g., Andretta et al., 2014; Worrell et al., 2019). This conversion yielded comparable scores that are easily interpretable.

Third, the relationship between profiles and distal outcomes (emotional well-being, social well-being, psychological well-being, depression, anxiety, and stress) was examined to test the second hypothesis. This was achieved by using the auxiliary variable function (DU3STEP) from the automatic three-step method in Mplus. This function allows the relationships between profiles and other continuous variables to be explored, correcting the class classification error and assuming that the variances of the distal outcomes vary across latent profiles (Asparouhov \& Muthén, 2014).

\section{Results}

\subsection{Preliminary analyses and measurement fit indices}

Descriptive statistics and correlations of the variables are presented in Tables S1 and S2. All AATI-TA subscales had significant correlations with well-being and psychological distress variables. Emotional, social, and psychological well-being were correlated positively with the three positive times (present, past, and future) and negatively correlated with the three negative times (present, past, and future). Conversely, depression, anxiety, and stress demonstrated positive correlations with all negative times and negative correlations with all positive times.

The results from the assessment of the measurement models are presented in Table 1. Comparing the three AATI-TA measurement models (two, three, and six factors), only the six-factor model was well fitted to the data. The MHC-SF and the DASS-21 were both well fitted to the data.

Table 1

Model fit indices of the measurement models.

\begin{tabular}{|c|c|c|c|c|c|c|c|c|}
\hline Scales & Model & CFI & TLI & SRMR & RMSEA [CI] & $\chi_{(\mathrm{df})}^{2}$ & $p$ & BIC \\
\hline \multirow[t]{3}{*}{ ATI-TA } & Two-factor & 0.480 & 0.428 & .190 & .155 [.149-.161] & $2163.08_{(251)}$ & .000 & 21386.49 \\
\hline & Three-factor & 0.832 & 0.814 & .090 & $.089[.082-.095]$ & $867.29_{(249)}$ & .000 & 19790.82 \\
\hline & Six-factor & 0.946 & 0.938 & .050 & $.052[.044-.059]$ & $434.04_{(237)}$ & .000 & 19319.21 \\
\hline MHC-SF & Three-factor & 0.940 & 0.926 & .050 & .060 [.047-.073] & $156.27_{(74)}$ & .000 & 12848.74 \\
\hline DASS-21 & Three-factor & 0.911 & 0.898 & .052 & $.052[.044-.061]$ & $342.67_{(183)}$ & .000 & 16471.54 \\
\hline
\end{tabular}


Table 2

Fit indices of models containing two to seven latent profiles.

\begin{tabular}{|c|c|c|c|c|c|c|c|}
\hline K & AIC & BIC & $\mathrm{aBIC}$ & Entropy & LMR $p$ & $\begin{array}{l}\text { aLMR } \\
p\end{array}$ & BLRT $p$ \\
\hline 2 & 3363.59 & 3435.00 & 3374.74 & .920 & .002 & .002 & $\leq 0.001$ \\
\hline 3 & 3132.48 & 3230.21 & 3147.74 & .870 & .266 & .272 & $\leq 0.001$ \\
\hline 4 & 2900.80 & 3024.85 & 2920.18 & .908 & .003 & .004 & $\leq 0.001$ \\
\hline 5 & 2803.36 & 2953.71 & 2826.84 & .913 & .207 & .216 & $\leq 0.001$ \\
\hline 6 & 2737.74 & 2914.41 & 2765.33 & .914 & .468 & .474 & $\leq 0.001$ \\
\hline 7 & 2676.32 & 2879.30 & 2728.02 & .883 & .071 & .074 & $\leq 0.001$ \\
\hline
\end{tabular}

\subsection{Latent profile analysis}

Table 2 presents the fit indices for the assessed competitive latent profile models. According to the BLRT, the four-profile solution should be selected since the BLRT was significant for all models. By contrast, the seven-profile model presented the lowest AIC and BIC. However - and relying on the posterior classification probabilities - the four-profile model had greater classification probabilities ( 0.90 and above) than the seven-profile model ( 0.85 and above), suggesting good discriminability and reliability (a probability value greater than 0.70 suggests a satisfactory fit; Nagin, 2015). Accordingly, the four-profile model appeared to be the optimal solution for the current sample, with a high entropy value of 0.90 , which indicates that $90 \%$ of participants were correctly classified into the appropriate latent profile (Clark \& Muthén, 2009). Moreover, the smallest profile contained more than 5\% of the sample, which is the percentage needed to sustain the validity of a class membership (Hipp \& Bauer, 2006; see Table S3).

Table 3 presents the mean AATI-TA subscale scores across the four latent profiles, while Fig. 1 presents them as a visual illustration. After we standardized the means into $T$-scores, Profile 1 made up $11 \%$ of the test sample $(n=35)$ and was labeled (past, present, and future) "negatives" due to the high mean scores on every negative subscale, with all standardized scores ranging between 0.5 and 1.5 SD, whereas positive mean scores ranged between -0.5 and -1.0 SD. Profile 2 made up $45 \%$ of the test sample ( $n=142$ ) and was labeled (past, present, and future) "positives" due to the high mean scores on the past and present positive subscales with more than 1 SD above the mean and the future positive subscale with 0.4 SD above the mean. By contrast, mean scores of negative subscales were 0.5 SD below average. Profile 3 made up $17 \%$ of the test sample $(n=53)$ and was labeled "past negatives" due to the high mean scores on the past negative subscales with more than $1.5 \mathrm{SD}$ above the mean and the past positive mean scores with more than $1.5 \mathrm{SD}$ below the mean. The mean scores for the present and future subscales (positive and negative) were all close to the mean ( $< \pm 0.5$ SD). Profile 4 made up $27 \%$ of the test sample $(n=87)$ and was labeled "present/future negatives" due to the high mean scores on present and future negative subscales, with more than $1.5 \mathrm{SD}$ above the mean. Mean scores for present and future positives subscales were between 0.5

Table 3

Mean scores on AATI-TA subscales across latent profiles.

\begin{tabular}{|c|c|c|c|c|}
\hline Variables & $\begin{array}{l}\text { Profile } 1 \\
\text { Negatives }(n=35 ; 11 \%)\end{array}$ & $\begin{array}{l}\text { Profile } 2 \\
\text { Positives ( } \mathrm{n}=142 ; 45 \%)\end{array}$ & $\begin{array}{l}\text { Profile } 3 \\
\text { Past negatives }(n=53 ; 17 \%)\end{array}$ & $\begin{array}{l}\text { Profile } 4 \\
\text { Present/future negatives }(n=87 ; 27 \%)\end{array}$ \\
\hline Past positive & $-0.90(0.13)$ & $0.57(0.03)$ & $-1.06(0.08)$ & $0.02(0.09)$ \\
\hline Past negative & $1.40(0.20)$ & $-0.71(0.03)$ & $1.58(0.10)$ & $-0.29(0.11)$ \\
\hline Present positive & $-0.90(0.11)$ & $0.56(0.05)$ & $0.02(0.08)$ & $-0.58(0.11)$ \\
\hline Present negative & $0.90(0.09)$ & $-0.46(0.04)$ & $0.08(0.06)$ & $0.35(0.08)$ \\
\hline Future positive & $-0.55(0.07)$ & $0.20(0.04)$ & $0.30(0.05)$ & $-0.29(0.05)$ \\
\hline Future negative & $0.89(0.11)$ & $-0.28(0.03)$ & $-0.17(0.04)$ & $0.22(0.06)$ \\
\hline
\end{tabular}

Note. Profile 1 (negatives) and 2 (positives) are past, present, and future, respectively.

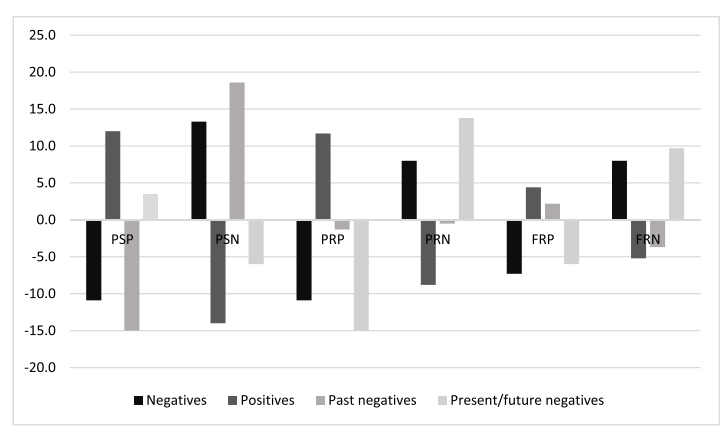

Note. PSP: Past positive; PSN: Past negative; PRP: Present positive; PRN: Present negative; FTP: Future positive; FTN: Future negative

Fig. 1. Latent time attitude profiles. Note. PSP: Past positive; PSN: Past negative; PRP: Present positive; PRN: Present negative; FTP: Future positive; FTN: Future negative. 
and 1.5 SD below the mean. The mean scores for the past positive and negative subscales were close to 0.5 SD above and below the mean, respectively. All profiles retained the labels used in a previous study because the results yielded similar profiles with similar scores (Worrell et al., 2019).

\subsection{Relationships between time attitude profiles and mental health}

The equality of means of the distal outcomes was tested across the four latent profiles. Table 4 presents the mean scores across latent profiles on well-being (i.e., emotional, social, and psychological) and psychological distress (i.e., depression, anxiety, and stress). Based on Chi-square results and the Cohen's $d$ effect size, Table 5 presents the differences between profiles regarding distal outcomes.

Table 4

Mean scores across latent profiles on time attitude-related variables: well-being and psychological distress.

\begin{tabular}{|c|c|c|c|c|c|}
\hline \multirow[t]{2}{*}{ Outcome } & \multirow{2}{*}{$\frac{\text { Negatives }}{\mathrm{M}(\mathrm{SE})}$} & \multirow{2}{*}{$\frac{\text { Positives }}{\mathrm{M}(\mathrm{SE})}$} & \multirow{2}{*}{$\frac{\text { Past negatives }}{\mathrm{M}(\mathrm{SE})}$} & \multirow{2}{*}{$\frac{\text { Present/Future negatives }}{\mathrm{M}(\mathrm{SE})}$} & \multirow[t]{2}{*}{ Significant differences between profiles } \\
\hline & & & & & \\
\hline Emotional well-being & $-0.92(0.15)$ & $0.42(0.04)$ & $0.09(0.06)$ & $-0.25(0.06)$ & $1<4<3<2$ \\
\hline Social well-being & $-0.68(0.12)$ & $0.41(0.04)$ & $-0.04(0.08)$ & $-0.25(0.06)$ & $1<4=3<2$ \\
\hline Psychological well-being & $-1.20(0.18)$ & $0.52(0.04)$ & $0.15(0.07)$ & $-0.30(0.06)$ & $1<4<3<2$ \\
\hline Depression & $0.73(0.12)$ & $-0.40(0.03)$ & $0.11(0.07)$ & $0.18(0.04)$ & $2<3=4<1$ \\
\hline Anxiety & $0.26(0.05)$ & $-0.16(0.01)$ & $0.07(0.03)$ & $0.06(0.02)$ & $2<4=3<1$ \\
\hline Stress & $0.32(0.06)$ & $-0.19(0.02)$ & $0.09(0.04)$ & $0.07(0.02)$ & $2<4=3<1$ \\
\hline
\end{tabular}

Note. " =" the groups are not significantly different.

Table 5

Chi square statistics and Cohen's d for pairwise differences between profiles.

\begin{tabular}{|c|c|c|c|c|c|c|c|c|c|c|c|c|c|}
\hline & \multicolumn{2}{|c|}{ Profile 1 vs. 2} & \multicolumn{2}{|c|}{ Profile 1 vs. 3} & \multicolumn{2}{|c|}{ Profile 1 vs. 4} & \multicolumn{2}{|c|}{ Profile 2 vs. 3} & \multicolumn{2}{|c|}{ Profile 2 vs. 4} & \multicolumn{2}{|c|}{ Profile 3 vs. 4} & \multirow[b]{2}{*}{ Overall $\chi^{2}$} \\
\hline & $\chi^{2}$ & $d$ & $\chi^{2}$ & $d$ & $\chi^{2}$ & $d$ & $\chi^{2}$ & $d$ & $\chi^{2}$ & $d$ & $\chi^{2}$ & $d$ & \\
\hline Emotional & $66.96^{\mathrm{a}}$ & -10.86 & $37.47^{\mathrm{a}}$ & -8.11 & $12.62^{\mathrm{a}}$ & -4.66 & $19.31^{\mathrm{a}}$ & 5.69 & $90.57^{\mathrm{a}}$ & 10.92 & $14.94^{\mathrm{a}}$ & 5.52 & $183.90^{\mathrm{a}}$ \\
\hline Social & $65.32^{\mathrm{a}}$ & -11.40 & $18.21^{\mathrm{a}}$ & -6.28 & $8.21^{\mathrm{a}}$ & -4.11 & $23.25^{\mathrm{a}}$ & 6.01 & $76.59^{\mathrm{a}}$ & 12.36 & 4.50 & 3.54 & $128.74^{\mathrm{a}}$ \\
\hline Psychological & $85.04^{\mathrm{a}}$ & -12.58 & $47.78^{\mathrm{a}}$ & -9.81 & $21.28^{\mathrm{a}}$ & -6.15 & $16.84^{\mathrm{a}}$ & 5.26 & $113.96 .^{\mathrm{a}}$ & 14.03 & $21.38^{\mathrm{a}}$ & 7.14 & $176.65^{\mathrm{a}}$ \\
\hline Depression & $84.90^{\mathrm{a}}$ & 12.35 & $17.55^{\mathrm{a}}$ & 5.98 & $18.13^{\mathrm{a}}$ & 5.44 & $39.25^{\mathrm{a}}$ & -7.80 & $119.11^{\mathrm{a}}$ & -14.07 & 0.46 & -1.65 & $204.39^{\mathrm{a}}$ \\
\hline Anxiety & $69.00^{\mathrm{a}}$ & 13.38 & $10.10^{\mathrm{a}}$ & 5.37 & $15.21^{\mathrm{a}}$ & 6.32 & $38.51^{\mathrm{a}}$ & -8.94 & $68.51^{\mathrm{a}}$ & -12.01 & 0.14 & 0.39 & $128.02^{\mathrm{a}}$ \\
\hline Stress & $55.90^{\mathrm{a}}$ & 9.91 & $7.98^{\mathrm{a}}$ & 4.51 & $12.32^{\mathrm{a}}$ & 5.48 & $31.28^{\mathrm{a}}$ & -6.79 & $39.39^{\mathrm{a}}$ & -7.0 & 0.63 & 0.85 & $84.90^{\mathrm{a}}$ \\
\hline
\end{tabular}

Note: Wald $\chi^{2}$ test, $d f=3$; $d$ : Cohen's d; Emotional, Social, and Psychological refers to each dimension of well-being assessed by MHC; Profile 1: Negatives; Profile 2: Positives; Profile 3: Past negatives; Profile 4: Present/future negatives.

${ }^{\mathrm{a}}$ The level of significance for relations was adjusted at $\mathrm{p}<.008$ using the Bonferroni correction.

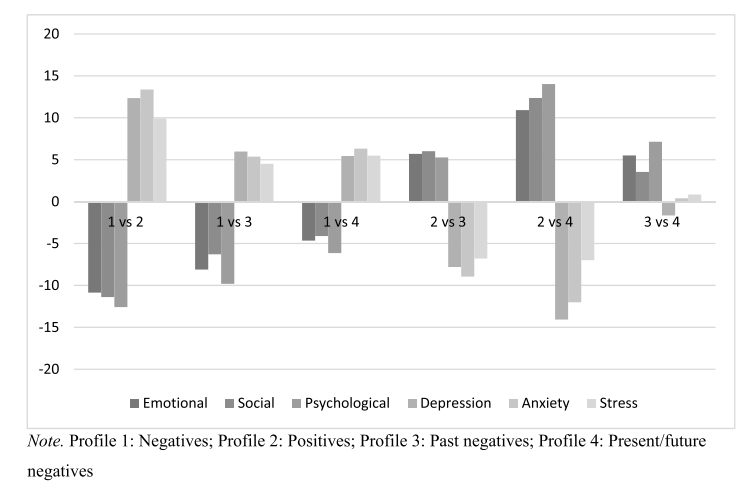

Fig. 2. Differences in effect sizes (Cohen's d) between profiles in their relationship to distal outcomes. Note. Profile 1: Negatives; Profile 2: Positives; Profile 3: Past negatives; Profile 4: Present/future negatives. 


\subsection{Well-being}

The positive group had significantly higher mean scores on emotional, social, and psychological well-being than all other profiles. By contrast, the negative group demonstrated significantly lower mean scores on all three types of well-being than the other profiles. The past negative group demonstrated positive mean scores on emotional and psychological well-being but negative mean scores on social well-being. The mean scores for the present/future negative group were negative for all three types of well-being. Psychological well-being had the highest mean scores (in either a positive or a negative direction) for all four profiles. Taken together, the results demonstrated that the positive group, followed by the past negative group, reported the highest levels of well-being, whereas the negative group reported the lowest.

\subsection{Psychological distress}

The positive group had significantly lower mean scores on depression, anxiety, and stress than all other profiles. By contrast, the negative group showed significantly higher scores on all three psychological distress indicators than the rest of the profiles. There were no significant differences between the past negatives and present/future negatives, but both groups achieved higher scores on depression, anxiety, and stress than the positive group and lower scores than the negative group. Depression was the psychological indicator with the highest mean scores (in either a positive or a negative direction).

Based on Chi-square and Cohen's $d$ results (see Fig. 2), the primary differences in well-being and psychological distress were observed between the positive and present/future negative groups, and between the negative and positive groups. The comparisons between the negative and present/future negative profiles revealed fewer differences. In general, depression and psychological wellbeing demonstrated the greatest differences between those groups.

\section{Discussion}

Adolescents can have different feelings and attitudes towards the past, present, and future. During adolescence, individuals face several challenges and demands that can reduce their well-being (González-Carrasco et al., 2019) and increase the likelihood of psychological distress (Suldo et al., 2016). The study of time attitudes offers new possibilities to explore whether regarding time frames as positive or negative is likely to influence adolescents' mental health. By investigating time attitude profiles, we analyzed the associations between the various profiles and mental health. The results confirmed our hypotheses since the positive time attitude profile was related to higher levels of emotional, social, and psychological well-being and lower levels of depression, anxiety, and stress. Moreover, psychological well-being and depression were the constructs with higher and lower scores, respectively, than the other distal outcomes.

This study identified four time attitude profiles of adolescents (i.e., past, present, and future negatives; past, present, and future positives; past negatives; and present/future negatives). These profiles are similar to those identified in a previous study, which also found a higher number of individuals clustered in positive profiles than in negative profiles (Worrell et al., 2019). However, in the present study, other negative profiles were generated that, together, comprised more individuals than the positive profile. These results demonstrated that the positive and negative profiles were somewhat comparable in terms of prevalence, although previous research has demonstrated that individuals may change profiles over time (Konowalczyk et al., 2018).

In the current study, there was a strong relationship between the six AATI-TA subscales and dual-factor model of mental health. With regard to the distinction between mental health and psychological distress (Keyes, 2009), time attitude subscales demonstrated different relationships with each construct. Present and future AATI-TA subscales were moderately and strongly correlated, respectively, with emotional, social, and psychological well-being, and the highest correlation was found between the present positive and emotional well-being. By contrast, all AATI-TA subscales were weakly or moderately correlated with psychological distress, with the highest correlation being between present negative and depression. These results are consistent with previous studies in adults (Cole et al., 2017) and late adolescents (Worrell et al., 2019), suggesting that a positive attitude towards the present is related to optimal functioning.

In our results, the positive profile was characterized by positive attitudes towards all three time frames. Positive feelings towards the past, present, and future have been associated with different outcomes in previous literature. For example, feeling positive about the past has been linked to a warm, sentimental attitude about past recollections and used to predict the reminiscence of experiences and memories characterized by positive moods (Stolarski et al., 2018). Likewise, feeling positive about the present has been associated with well-being and positive social relationships (Boniwell et al., 2010; Stolarski et al., 2014). Finally, a study found that feeling positive about the future was more common in goal-oriented, motivational, and self-aware individuals with high intention-behavior consistency (Shipp et al., 2009). Adolescents clustered in this profile reported higher levels of emotional, social, and psychological well-being and lower levels of depression, anxiety, and stress. In addition, previous studies have found that positive time attitude profiles are associated with optimal outcomes (i.e., general well-being and psychological symptoms; Konowalczyk et al., 2018; Worrell et al., 2019).

The results of the current study also revealed three negative profiles that differed in their degree of negative feelings towards the past, present, or future. As expected, the past, present, and future negative profile was associated with the poorest outcomes in terms of well-being and psychological distress. Nevertheless, the primary difference between the other two negative profiles was that participants in the present/future negative group reported decreased emotional and psychological well-being compared to those in the past negative group. Previous literature supports these findings since Rönnlund et al. (2017) found the future negative profile to be a 
stronger predictor of negative moods and decreased well-being. On the other hand, the present negative profile was linked to increased depression symptoms, an unclear vision of the future, and a tendency to disregard future consequences of behaviors (McElwee \& Haugh, 2010; Zimbardo \& Boyd, 1999). Generally, our findings are in line with Worrell et al. (2019), suggesting that the past, present, and future negative and the present/future negative profiles are correlated with the most detrimental outcomes.

In line with the dual-factor model of mental health, we observed lower levels of psychological distress when higher scores on emotional, social, and psychological well-being were reported. Psychological well-being and depression demonstrated the highest (for both positive and negative) scores across all profiles. Psychological well-being may be the most relevant aspect of mental health during adolescence (González-Carrasco et al., 2019); having meaningful goals during transitional stages helps adolescents face various demands and, in most cases, eases the pursuit of a fulfilling life (Vitters $\varnothing, 2016)$. By contrast, depression is the most prevalent form of psychological distress among adolescents and has been widely demonstrated to have a negative relationship with optimal development (Birmaher et al., 1996). Depression has been associated with poorer social relationships and academic outcomes, substance abuse, increased risk of suicide, and malfunctioning in adolescents (Beesdo et al., 2009; Birmaher et al., 1996; Derdikman-Eiron et al., 2011). Altogether, positive feelings about time may ensure positive mental health and optimal psychological functioning. This highlights the need to promote more positive feelings towards the past, present, and future.

\subsection{Implications}

This study has revealed that time attitudes are meaningful constructs in the study of mental health. Feeling positive towards the past, present, and future may enhance well-being and protect against psychological distress, suggesting that this type of profile is one of the most adaptive in adolescents. By contrast, feeling negative towards the past, present, and future may be counterproductive. These findings have important implications for developing interventions to target the promotion of mental health during adolescence. Previous studies on future time orientation interventions have demonstrated that time perspective can be modified (Oyserman et al., 2002). Therefore, the development of time perspective interventions based on positive psychology may influence individuals' tendencies to adopt a specific time perspective (Miller \& Nickerson, 2008). Educational experiences shape one's time perspective and time attitudes, as adolescents spend much of their time in school. For this reason, time perspective-based interventions in the school context may prove effective in improving adolescents' mental health (Boniwell et al., 2015).

These interventions might be of assistance to students whose mental health is at risk and in promoting adolescents' general mental health. Strategies underpinning positive psychology interventions that focus on the enhancement of well-being and that, as a consequence, reduce psychological distress, are considered efficient science-based practices in the school context (Tejada-Gallardo et al., 2020). These interventions target components that can work on time frames and are based on fostering positive functioning and well-being. For example, gratitude practices targeting the past may boost positive attitudes towards the past (Seligman et al., 2005), savoring the present may develop positive present attitudes (Smith et al., 2014), and reflecting on our best future may promote positive attitudes towards the future (Sheldon \& Lyubomirsky, 2006).

\subsection{Limitations and future research}

The results of this study should be understood in the context of a number of limitations. First, all data were collected through selfreporting, which can bias responses. Second, the design of the study was cross-sectional, and it is not possible to attribute causality in the results. Future longitudinal studies are needed to better understand the relationship between time attitudes and the dual-factor model of mental health in adolescents. It may be interesting to establish whether these profiles are consistent across countries, and cross-cultural research is therefore needed. This study has revealed a pattern of results similar to those of previous studies, demonstrating that well-being and psychological distress are related to time attitudes. For this reason, future research should go one step further and examine how time attitudes might change over time through interventions aimed at increasing well-being and reducing psychological distress.

\section{Acknowledgement}

This work was supported by a doctoral scholarship from the University of Lleida.

\section{Appendix A. Supplementary data}

Supplementary data to this article can be found online at https://doi.org/10.1016/j.adolescence.2021.04.002.

\section{References}

Andretta, J. R., Worrell, F. C., \& Mello, Z. R. (2014). Predicting educational outcomes and psychological well-being in adolescents using time attitude profiles. Psychology in the Schools, 51(5), 434-451. https://doi.org/10.1002/pits.21762.

Asparouhov, T., \& Muthén, B. (2014). Auxiliary variables in mixture modeling: Three-step approaches using Mplus. Structural Equation Modeling, 21(3), 329-341. https://doi.org/10.1080/10705511.2014.915181. 
Beesdo, K., Knappe, S., \& Pine, D. S. (2009). Anxiety and anxiety disorders in children and adolescents: Developmental issues and implications for DSM-V. Psychiatric Clinics of North America, 32(3), 483-524. https://doi.org/10.1016/j.psc.2009.06.002.

Berlin, K. S., Williams, N. A., \& Parra, G. R. (2014). An introduction to latent variable mixture modeling (Part 1): Overview and cross-sectional latent class and latent profile analyses. Journal of Pediatric Psychology. https://doi.org/10.1093/jpepsy/jst084.

Birmaher, B., Ryan, N. D., Williamson, D. E., Brent, D. A., Kaufman, J., Dahl, R. E., Perel, J., \& Nelson, B. (1996). Childhood and adolescent depression: A review of the past 10 years. Part I. Journal of the American Academy of Child \& Adolescent Psychiatry, 35(11), 1427-1439. https://doi.org/10.1097/00004583-19961100000011.

Boniwell, I., Osin, E., Alex Linley, P., \& Ivanchenko, G. V. (2010). A question of balance: Time perspective and well-being in British and Russian samples. The Journal of Positive Psychology, 5(1), 24-40. https://doi.org/10.1080/17439760903271181.

Boniwell, I., Osin, E. N., \& Martinez, C. (2015). Teaching happiness at school: Non-randomised controlled mixed-methods feasibility study on the effectiveness of Personal well-being lessons. The Journal of Positive Psychology, 11(1), 85-98. https://doi.org/10.1080/17439760.2015.1025422.

Boniwell, I., \& Zimbardo, P. (2004). Balancing time perspective in pursuit of optimal functioning. In P. A. Linley, \& S. Joseph (Eds.), Positive psychology in practice (pp. 165-178). John Wiley \& Sons.

Byrne, B. M. (1995). Structural equation modeling with EQS and EQS/Windows: Basic concepts, applications, and programming. Sage Publications. https://doi.org/ $10.2307 / 3151989$.

Chen, X., \& Page, A. (2016). Stability and instability of subjective well-being in the transition from adolescence to young adulthood: Longitudinal evidence from 20991 young Australians. PloS One, 11(5). https://doi.org/10.1371/journal.pone.0156399.

Clark, S., \& Muthén, B. O. (2009). Relating latent class analysis results to variables not included in the nalysis. Statistical Innovations, 1-55.

Clonan, S. M., Chafouleas, S. M., McDougal, J. L., \& Riley-Tillman, T. C. (2004). Positive psychology goes to school: Are we there yet? Psychology in the Schools, 41(1), 101-110. https://doi.org/10.1002/pits.10142.

Cole, J. C., Andretta, J. R., \& McKay, M. T. (2017). An exploratory examination of the viability and meaningfulness of time attitudes profiles in adults. Personality and Individual Differences, 106, 146-151. https://doi.org/10.1016/j.paid.2016.10.046.

Daza, P., Novy, D. M., Stanley, M. A., \& Averill, P. (2002). The depression anxiety stress scale-21: Spanish translation and validation with a hispanic sample. Journal of Psychopathology and Behavioral Assessment, 24(3), 195-205. https://doi.org/10.1023/A:1016014818163.

Derdikman-Eiron, R., Indredavik, M. S., Bratberg, G. H., Taraldsen, G., Bakken, I. J., \& Colton, M. (2011). Gender differences in subjective well-being, self-esteem and psychosocial functioning in adolescents with symptoms of anxiety and depression: Findings from the Nord-Trøndelag health study. Scandinavian Journal of Psychology, 52(3), 261-267. https://doi.org/10.1111/j.1467-9450.2010.00859.x.

Derdikman-Eiron, R., Hjemdal, O., Lydersen, S., Bratberg, G. H., \& Indredavik, M. S. (2013). Adolescent predictors and associates of psychosocial functioning in young men and women: 11 year follow-up findings from the nord-trøndelag health study. Scandinavian Journal of Psychology, 54(2), 95-101. https://doi.org/10.1111/ sjop. 12036.

Echeverría, G., Torres, M., Pedrals, N., Padilla, O., Rigotti, A., \& Bitran, M. (2017). Validación de la versión en español del cuestionario del continuo de salud mentalversión corta. Psicothema, 29(1), 96-102. https://doi.org/10.7334/psicothema2016.3.

González-Carrasco, M., Vaqué, C., Malo, S., Crous, G., Casas, F., \& Figuer, C. (2019). A Qualitative longitudinal study on the well-being of children and adolescents. Child Indicators Research, 12(2), 479-499. https://doi.org/10.1007/s12187-018-9534-7.

Hallam, W. T., Olsson, C. A., O'Connor, M., Hawkins, M., Toumbourou, J. W., Bowes, G., McGee, R., \& Sanson, A. (2014). Association between adolescent eudaimonic behaviours and emotional competence in young adulthood. Journal of Happiness Studies, 15(5), 1165-1177. https://doi.org/10.1007/s10902-013-9469-0.

Hammen, C. (2005). Stress and depression. Annual Review of Clinical Psychology, 293-319. https://doi.org/10.1146/annurev.clinpsy.1.102803.143938.

Hipp, J. R., \& Bauer, D. J. (2006). Local solutions in the estimation of growth mixture models. Psychological Methods, 11(1), 36-53. https://doi.org/10.1037/1082989X.11.1.36.

Keyes, L. M. (2002). The mental health continuum: From languishing to flourishing in life. Journal of Health and Social Behavior, 43(2), 207-222. https://doi.org/ 10.2307/3090197.

Keyes, L. M. (2009). The nature and importance of positive mental health in America's adolescents. In R. Gilman, E. S. Huebner, \& M. J. Furlong (Eds.), Handbook of positive psychology in schools (pp. 1-502). Routledge. https://doi.org/10.4324/9780203884089.

Keyes, C. L. M., Wissing, M., Potgieter, J. P., Temane, M., Kruger, A., \& van Rooy, S. (2008). Evaluation of the mental health continuum-short form (MHC-SF) in Setswana-speaking South Africans. Clinical Psychology \& Psychotherapy, 15(3), 181-192. https://doi.org/10.1002/cpp.572.

Kline, R. (2011). Principles and practice of structural equation modeling (3 ${ }^{\text {rd }}$ ed.). The Guildford Press. https://doi.org/10.15353/cgjsc-rcessc.v1i1.25.

Konowalczyk, S., McKay, M. T., Wells, K. E., \& Cole, J. C. (2018). The influence of time attitudes profile membership on mental well-being and psychosomatic symptomatology: A United Kingdom-based prospective study. Psychiatry Research, 261, 375-382. https://doi.org/10.1016/j.psychres.2017.12.071.

Konowalczyk, S., Rade, F. C. A., \& Mello, Z. R. (2019). Time perspective, sports club membership, and physical self-concept among adolescents: A person-centered approach. Journal of Adolescence, 72, 141-151. https://doi.org/10.1016/j.adolescence.2019.02.008.

La Guardia, J., \& Ryan, R. (2002). What adolescents need: A self-determination theory perspective on development within families, school, and society. In F. Pajares, \& T. Urdan (Eds.), Academic motivation of adolescents (pp. 193-219). Information Age Publishing.

Lanza, S. T., Rhoades, B. L., Nix, R. L., \& Greenberg, M. T. (2010). Modeling the interplay of multilevel risk factors for future academic and behavior problems: A person-centered approach. Development and Psychopathology, 22(2), 313-335. https://doi.org/10.1017/S0954579410000088.

Lanza, S. T., Tan, X., \& Bray, B. C. (2013). Latent class analysis with distal outcomes: A flexible model-based approach. Structural Equation Modeling, 20(1), 1-26. https://doi.org/10.1080/10705511.2013.742377.

Laursen, B., \& Hoff, E. (2006). Person-centered and variable-centered approaches to longitudinal data. Merrill-Palmer Quarterly, 52(3), 377-389. https://doi.org/ 10.1353/mpq.2006.0029.

Lovibond, S. H., \& Lovibond, P. F. (1995). Manual for the depression anxiety stress scales (2 ${ }^{\text {nd }}$ ed.). Psychology Foundation. https://doi.org/10.1016/0005-7967(94) 00075-U.

Marsh, H. W., Hau, K. T., \& Wen, Z. (2004). In search of golden rules: Comment on hypothesis-testing approaches to setting cutoff values for fit indexes and dangers in overgeneralizing Hu and Bentler's (1999) findings. Structural Equation Modeling, 11(3), 320-341. https://doi.org/10.1207/s15328007sem1103_2.

McElwee, R. O. B., \& Haugh, J. A. (2010). Thinking clearly versus frequently about the future self: Exploring this distinction and its relation to possible selves. Self and Identity, 9(3), 298-321. https://doi.org/10.1080/15298860903054290.

McKay, M. T., Morgan, G. B., Wells, K. E., Worrell, F., Cole, J. C., \& Andretta, J. R. ( (2019). The influence of time attitudes on adolescent alcohol use behaviours: A 33month prospective study in the United Kingdom. Addiction Research and Theory, 27(3), 189-197. https://doi.org/10.1080/16066359.2018.1478414.

Mello, Z., \& Worrell, F. (2007). The adolescent time inventory-English. Unpublished Scale. Berkeley, CA: Graduate School of Education University of California.

Mello, Z. R., \& Worrell, F. C. (2015). The past, the present, and the future: A conceptual model of time perspective in adolescence. In M. Stolarski, N. Fieulaine, \& W. van Beek (Eds.), Time perspective theory; review, research and application (pp. 115-129). Springer International Publishing. https://doi.org/10.1007/978-3-31907368-2 7 .

Mello, Z. R., Worrell, F., Anguiano, R., \& Mendoza-Denton, R. (2010). The adolescent time attitude scale - Spanish version. Unpublished Scale. Berkeley, CA: The University of Colorado, CO Springs and the University of California.

Miller, D. N., \& Nickerson, A. B. (2008). Changing the past, present, and future: Potential applications of positive psychology in school-based psychotherapy with children and youth. Journal of Applied School Psychology, 24(1), 147-162. https://doi.org/10.1300/J370v24n01_08.

Morgan, G. B., Wells, K. E., Andretta, J. R., \& McKay, M. T. (2016). Temporal attitudes profile transition among adolescents: A longitudinal examination using moverstayer latent transition analysis. Psychological Assessment, 29(7), 890-901. https://doi.org/10.1037/pas0000383.

Muthén, L. K., \& Muthén, B. O. (2012). Mplus user's guide (6 ${ }^{\text {th }}$ ed.). Muthén \& Muthén.

Nagin, D. (2015). Group-based modeling of development. Harvard University Press. https://doi.org/10.4159/9780674041318. 
Ng, E. C. W., \& Fisher, A. T. (2013). Understanding well-being in multi-levels: A review. Health, Culture and Society, 5(1), 308-323. https://doi.org/10.5195/ hcs.2013.142.

Nylund, K. L., Asparouhov, T., \& Muthén, B. O. (2007). Deciding on the number of classes in latent class analysis and growth mixture modeling: A Monte Carlo simulation study. Structural Equation Modeling, 14(4), 535-569. https://doi.org/10.1080/10705510701575396.

Oberski, D. (2016). Mixture models: Latent profile and latent class analysis. In J. Robertson, \& M. Kaptein (Eds.), Modern statistical methods for HCI (pp. 275-287). Springer. https://doi.org/10.1007/978-3-319-26633-6_12.

Oyserman, D., Terry, K., \& Bybee, D. (2002). A possible selves intervention to enhance school involvement. Journal of Adolescence, 25(3), 313-326. https://doi.org/ 10.1006/jado.2002.0474.

Paus, T., Keshavan, M., \& Giedd, J. N. (2008). Why do many psychiatric disorders emerge during adolescence? Nature Reviews Neuroscience, 9(12), 947-957. https:// doi.org/10.1038/nrn2513.

Pearson, C., Janz, T., \& Ali, J. (2013). Mental and substance abuse disorders in Canada. Health at a Glance, 82, 1-8.

Piaget, J. (1955). The development of time concepts in the child. In P. H. Hoch, \& J. Zubin (Eds.), Psychopathology of childhood (pp. 34-44). Grube and Stratton.

Rönnlund, M., Aström, E., \& Carelli, M. G. (2017). Time perspective in late adulthood: Aging patterns in past, present and future dimensions, deviations from balance, and associations with subjective well-being. Timing \& Time Perception, 5(1), 77-98. https://doi.org/10.1163/22134468-00002081.

Seligman, M., Steen, T. A., Park, N., \& Peterson, C. (2005). Positive psychology progress: Empirical validation of interventions. American Psychologist, 60(5), 410-421. https://doi.org/10.1037/0003-066X.60.5.410.

Shapero, B. G., Hankin, B. L., \& Barrocas, A. L. (2013). Stress generation and exposure in a multi-wave study of adolescents: Transactional processes and sex differences. Journal of Social and Clinical Psychology, 32(9), 989-1012. https://doi.org/10.1521/jscp.2013.32.9.989.

Sheldon, K. M., \& Lyubomirsky, S. (2006). How to increase and sustain positive emotion: The effects of expressing gratitude and visualizing best possible selves. The Journal of Positive Psychology, 1(2), 73-82. https://doi.org/10.1080/17439760500510676.

Shipp, A. J., Edwards, J. R., \& Lambert, L. S. (2009). Conceptualization and measurement of temporal focus: The subjective experience of the past, present, and future. Organizational Behavior and Human Decision Processes, 110(1), 1-22. https://doi.org/10.1016/j.obhdp.2009.05.001.

Smith, J., Harrison, P., Kurtz, J. L., \& Bryant, F. (2014). Nurturing the capacity to savor. Interventions to enhance the enjoyment of positive experiences. In A. Park, \& S. Schueller (Eds.), The wiley blackwell handbook of positive psychological interventions (pp. 42-65). John Wiley \& Sons. https://doi.org/10.1002/9781118315927.

Stolarski, M., Fieulaine, N., \& Zimbardo, P. G. (2018). Putting time in a wider perspective: The past, the present and the future of time perspective theory. In V. Zeigler-Hill, \& T. K. Shackelford (Eds.), The SAGE Handbook of Personality and individual differences (pp. 592-628). Sage Publications. https://doi.org/10.4135/ 9781526451163.n28.

Stolarski, M., Matthews, G., Postek, S., Zimbardo, P. G., \& Bitner, J. (2014). How we feel is a matter of time: Relationships between time perspectives and mood. Journal of Happiness Studies, 15(4), 809-827. https://doi.org/10.1007/s10902-013-9450-y.

Suldo, S. M., Thalji-Raitano, A., Kiefer, S. M., \& Ferron, J. M. (2016). Conceptualizing high school students' mental health through a dual-factor model. School Psychology Review, 45(4), 434-457. https://doi.org/10.17105/SPR45-4.434-457.

Tein, J. Y., Coxe, S., \& Cham, H. (2013). Statistical power to detect the correct number of classes in latent profile analysis. Structural Equation Modeling, 20(4), 640-657. https://doi.org/10.1080/10705511.2013.824781.

Tejada-Gallardo, C., Blasco-Belled, A., Torrelles-Nadal, C., \& Alsinet, C. (2020). Effects of school-based multicomponent positive psychology interventions on wellbeing and distress in adolescents: A systematic review and meta-analysis. Journal of Youth and Adolescence, 49(10), 1943-1960. https://doi.org/10.1007/s10964020-01289-9.

Vittersø, J. (2016). The most important idea in the world: An introduction. In J. Vittersø (Ed.), Handbook of eudaimonic well-being (pp. 1-24). Springer International Publishing. https://doi.org/10.1007/978-3-319-42445-3_1.

Wang, M., \& Hanges, P. J. (2011). Latent class procedures: Applications to organizational research. Organizational Research Methods, 14(1), 24-31. https://doi.org/ $10.1177 / 1094428110383988$.

Wells, K. E., Morgan, G., Worrell, F. C., Sumnall, H., \& McKay, M. T. (2018). The influence of time attitudes on alcohol-related attitudes, behaviors and subjective life expectancy in early adolescence: A longitudinal examination using mover-stayer latent transition analysis. International Journal of Behavioral Development, 42(1), 93-105. https://doi.org/10.1177/0165025416679740.

Westerhof, G. J., \& Keyes, C. L. M. (2010). Mental illness and mental health: The two continua model across the lifespan. Journal of Adult Development, 17(2), 110-119. https://doi.org/10.1007/s10804-009-9082-y.

World Health Organization. (2004). Promoting mental health: Concepts, emerging evidence, practice: Summary report. Geneva.

World Health Organization. (2017). Depression and other common mental disorders global health estimates. Geneva.

Worrell, F. C., Andretta, J. R., Wells, K. E., Cole, J. C., \& McKay, M. T. (2019). Time attitudes and mental well-being, psychological, and somatic symptomatology in final year high school students. Current Psychology, 1-12. https://doi.org/10.1007/s12144-019-00386-8.

Zimbardo, P. G., \& Boyd, J. N. (1999). Putting time in perspective: A valid, reliable individual-differences metric. Journal of Personality and Social Psychology, 77(6), 1271-1288. https://doi.org/10.1037/0022-3514.77.6.1271. 